\title{
Dessecação da Brachiaria ruziziensis com paraquat antes da semeadura da
}

\author{
soja $\mathbf{a}^{1}$

\section{Desiccation of Brachiaria ruziziensis with paraquat before soybean sowing}

\author{
Neumárcio Vilanova Costa ${ }^{2}$; Devair Carlos de Andrade $^{3}$; Rodrigo Fernando Dourado ${ }^{3}$; \\ Guilherme Cardoso Pavan ${ }^{3}$; Andréia Cristina Peres Rodrigues da Costa ${ }^{4}$
}

\begin{abstract}
Resumo - São escassas na literatura as informações referentes à dessecação de Brachiaria ruziziensis, principalmente com o uso de herbicidas de ação de contato. Assim, objetivou-se avaliar diferentes doses e volumes de calda do paraquat no manejo da dessecação da forrageira $B$. ruziziensis e os efeitos na cultura da soja e na supressão das plantas daninhas. O delineamento experimental utilizado foi o de blocos casualizados, com quatro repetições. Os tratamentos foram dispostos num esquema fatorial $4 \times 6+1$, correspondente à avaliação de quatro doses do paraquat $\left(100,200,400\right.$ e $\left.800 \mathrm{~g} \mathrm{ha}^{-1}\right)$ em seis volumes de calda $\left(67,140,199,283,323\right.$ e $\left.396 \mathrm{~L} \mathrm{ha}^{-1}\right)$, além de uma testemunha sem aplicação. Para o estudo da dinâmica da população das plantas daninhas também foi utilizada uma testemunha em condição de pousio e outra somente com a cultura sem a presença de palha (capinada). Conclui-se que a dessecação de B. ruziziensis com paraquat foi eficiente até os 7 dias após a aplicação, sendo a maior eficiência obtida a partir da dose de $200 \mathrm{~g}$ $\mathrm{ha}^{-1}$, independentemente do volume de aplicação. A partir deste período as plantas da forrageira iniciaram um novo ciclo de crescimento e interferiram negativamente na produtividade da soja. A infestação das plantas daninhas foi reduzida nas áreas com B. ruziziensis em consórcio com a soja em relação à área em pousio.
\end{abstract}

Palavras-chaves: herbicida, plantio direto, planta daninha

Abstract - Information regarding the desiccation of Brachiaria ruziziensis are scarce in the literature, especially with the use of contact action herbicides. The objective was to evaluate different doses and spray volumes of paraquat in the management of the desiccation of the foraging B. ruziziensis and the effects on soybean crop and weed suppression. The experimental design was completely randomized block with four replications. The treatments were arranged in a factorial scheme $4 \times 6+1$, corresponding to the evaluation of four doses of paraquat $(100,200,400$, and $\left.800 \mathrm{~g} \mathrm{ha}^{-1}\right)$ in six spray volumes $\left(67,140,199,283,323\right.$, and $\left.396 \mathrm{~L} \mathrm{ha}^{-1}\right)$, besides a check without application. To study the population dynamics of the weeds was also used a control in fallow condition and another only with the crop without the presence of straw (weeded). It is concluded that the desiccation of $B$. ruziziensis with paraquat was effective to 7 days after application, being

\footnotetext{
${ }^{1}$ Recebido para publicação em 24/07/2014 e aceito em 29/07/2015.

${ }^{2}$ Docente do Centro de Ciências Agrárias da Universidade Estadual do Oeste do Paraná (Unioeste), Rua Pernambuco, C.P. 91, CEP 85960-000, Marechal Cândido Rondon, PR. E-mail: neumarcio.costa@unioeste.br. (*autor para correspondência)

${ }^{3}$ Discentes do curso de Agronomia da Universidade Estadual do Oeste do Paraná (Unioeste). Marechal Cândido Rondon, PR.

${ }^{4}$ Docente do Centro de Ciências Agrárias da Universidade Estadual de Maringá (UEM), Campus Regional de Umuarama, PR.
} 
the highest efficiency obtained from the dose of $200 \mathrm{~g} \mathrm{ha}^{-1}$, regardless of the spray volume used. From this period, the forage plants began a new cycle of growth and interfered negatively on soybean yield. The infestation of weeds was reduced in areas with B. ruziziensis in consortium with soybeans in relation to the fallow area.

Keywords: herbicide, no-tillage, weed

\section{Introdução}

A semeadura direta é caracterizada pelo reduzido revolvimento do solo e a formação de uma cobertura de restos vegetais sobre a superfície do solo, sendo que a manutenção dos restos vegetais na superfície do solo, além de protegê-lo da radiação solar, dissipa a energia de impacto das gotas de chuva, reduz a evaporação da água e aumenta a eficiência da ciclagem dos nutrientes (Araújo e Rodrigues, 2000, Severino e Christoffoleti, 2001).

A cobertura vegetal sobre o solo, pode ainda modificar e reduzir significativamente a intensidade de infestação de plantas daninhas em áreas agrícolas, devido às alterações das condições de germinação das sementes e emergência das plântulas, em razão do efeito físico da cobertura da palha e/ou da liberação de substâncias alelopáticas (Jakelaitis et al., 2003; Mateus et al., 2004).

Desta forma, dentre as espécies com potencial de utilização no sistema de plantio direto destaca-se Brachiaria ruziziensis Germain \& Evrard. Esta espécie é nativa da parte oriental da República do Zaire, em Ruanda e Quênia, sendo introduzida como forrageira em diversas partes do mundo, inclusive no Brasil (Kissmann e Groth, 1997).

No sistema de plantio direto o manejo das forrageiras antes da semeadura é normalmente realizado com herbicidas sistêmicos, contudo, herbicidas de contato também podem ser utilizados, a exemplo do paraquat.

O paraquat é aplicado em pósemergência, apresenta amplo espectro de ação, o que possibilita excelente controle de plantas daninhas anuais ou perenes, tanto de folhas largas como estreitas. Contudo, ainda não apresenta registro de uso para o manejo de dessecação de $B$. ruziziensis (Rodrigues e Almeida, 2011).

Como o paraquat apresenta ação de contato, torna-se fundamental a utilização de técnicas de aplicação que proporcionem os máximos de depósitos da calda em toda a biomassa do alvo. De acordo com Cunha et al. (2007), com a utilização de pontas de pulverização que produzam gotas muito finas $(<100 \mu \mathrm{m})$, geralmente, se consegue boa cobertura superficial e uniformidade de distribuição da calda, porém, essas gotas podem evaporar em condições de baixa umidade relativa ou serem levadas pela corrente de ar. Desta maneira, gotas finas não são recomendadas para aplicações de herbicidas e sim para outros produtos como fungicidas de contato.

Em contrapartida, pode-se aumentar a eficiência dos herbicidas de contato e reduzir os riscos de deriva das gotas com a utilização de pontas de pulverização que proporcionem gotas de diâmetro grande e em volumes que garantam boa cobertura. Bauer e Raetano (2004) citam que para o uso de doses e volumes reduzidos, a uniformidade na distribuição deve ser alcançada; caso contrário, a dose que chega ao alvo poderá ser insuficiente para causar o efeito biológico desejável, ou a dose poderá ser excessiva, determinando desperdício de produto, perdas e contaminação do ambiente.

$\mathrm{Na}$ literatura, são escassas informações referentes ao manejo químico de $B$. ruziziensis no período da dessecação. Portanto, as hipóteses do presente trabalho baseiam-se no fato de que para o manejo da dessecação de $B$. ruziziensis, a recomendação da dose do paraquat pode ser dependente do volume de calda utilizado. Além disso, a palhada remanescente pode auxiliar na supressão da emergência das plantas daninhas na cultura da soja. 
O objetivo do presente trabalho foi avaliar diferentes doses do paraquat e volumes de calda na dessecação da forrageira $B$. ruziziensis e os efeitos na cultura da soja e na supressão das plantas daninhas.

\section{Material e Métodos}

O experimento foi instalado na Estação Experimental da Universidade Estadual do Oeste do Paraná-Unioeste, no município de Marechal Cândido Rondon/PR. O solo da área experimental foi classificado como Latossolo Vermelho Distroférrico (LVdf), de textura argilosa, com boa drenagem (Embrapa, 1999), cultivado há sete anos no sistema de plantio direto na palha. A análise química apresentou as seguintes características: $\mathrm{pH}\left(\mathrm{CaCl}_{2}\right)=4,65$; matéria orgânica $\left(\mathrm{g} \mathrm{dm}^{-3}\right)=20,51 ; \mathrm{P}\left(\mathrm{mg} \mathrm{dm}^{-3}\right)$ $=13,05 ; \mathrm{H}+\mathrm{Al}, \mathrm{K}, \mathrm{Ca}, \mathrm{Mg}, \mathrm{SB}$ e CTC $\left(\mathrm{cmol}_{\mathrm{c}}\right.$ $\left.\mathrm{dm}^{-3}\right)=4,70 ; 0,38 ; 4,34 ; 1,77 ; 6,49$ e 11,19 ; respectivamente; e V\% $=58,00$; tendo em sua composição textural 10,79 \% de areia; $36,21 \%$ de silte e $53,00 \%$ de argila. Não foi feita a correção da acidez do solo.

Utilizou-se o delineamento experimental de blocos casualizados com quatro repetições. Os tratamentos foram dispostos num esquema fatorial $4 \times 6+1$, correspondente a quatro doses do paraquat $\left(100,200,400\right.$ e $800 \mathrm{~g} \mathrm{ha}^{-1}$ de ingrediente ativo) e seis volumes de calda (67, 140, 199, 283, 323 e $396 \mathrm{~L} \mathrm{ha}^{-1}$ ), além de uma testemunha sem aplicação. Para o estudo da dinâmica da população das plantas daninhas também foi utilizada uma testemunha em condição de pousio e outra somente com a cultura sem a presença de palha (capinada).

Foram utilizadas pontas de pulverização modelo Turbo Twinjet de jato plano duplo com ângulo entre cada jato de pulverização de $60^{\circ}$ $\left(30^{\circ}\right.$ para frente e $30^{\circ}$ para trás). As descrições das pontas de pulverização utilizadas para a obtenção dos volumes de calda estão descritas na Tabela 1 .

Tabela 1. Descrição das pontas de pulverização utilizadas para o manejo da dessecação de $B$. ruziziensis com diferentes doses do paraquat. Marechal Cândido Rondon/PR.

\begin{tabular}{cccccc}
\hline Ponta* & Descrição & $\begin{array}{c}\text { Volume de calda } \\
\left(\mathrm{L} \mathrm{ha}^{-1}\right)\end{array}$ & $\begin{array}{c}\text { Pressão } \\
(\mathrm{KPa})\end{array}$ & $\begin{array}{c}\text { Velocidade } \\
\left(\mathrm{km} \mathrm{h}^{-1}\right)\end{array}$ & Classificação das gotas \\
\hline Turbo Twinjet & TTJ6011002VP & 67 & 300 & 10 & Grossa \\
Turbo Twinjet & TTJ60110025VP & 140 & 380 & 6 & Muito grossa \\
Turbo Twinjet & TTJ6011003VP & 199 & 480 & 5 & Muito grossa \\
Turbo Twinjet & TTJ6011004VP & 283 & 400 & 3,6 & Muito grossa \\
Turbo Twinjet & TTJ6011005VP & 323 & 450 & 3,6 & Muito grossa \\
Turbo Twinjet & TTJ6011006VP & 396 & 550 & 3,6 & Extremamente grossa \\
\hline
\end{tabular}

*Spraying Systems Co. (2008). Gotas grossas (DMV = 250-375 $\mu \mathrm{m})$, Gotas muito grossas (DMV = 375-450 $\mu \mathrm{m})$ e Gotas extremamente grossas $(\mathrm{DMV}>450 \mu \mathrm{m})$.

A semeadura de $B$. ruziziensis $(27 / 11 / 2012)$ foi realizada utilizando-se uma semeadoura adaptada para o plantio de sementes de pastagem (COPAGRIL). Utilizou-se sementes incrustadas com germinação de $60 \%$ que foram misturadas ao adubo Super Fosfato Simples com $18 \%$ de $\mathrm{P}_{2} \mathrm{O}_{5}\left(155 \mathrm{~kg} \mathrm{ha}^{-1}\right.$ de SFS) para a distribuição de $10,0 \mathrm{~kg} \mathrm{ha}^{-1}$ de sementes da forrageira.

No período do mês de agosto ocorreram geadas que causaram efeito de dessecação nas plantas da forrageira, sendo que foi necessário realizar a roçagem e retirada mecânica da palhada em 30/08/2013. Posteriormente, no dia 15/10/13 foi realizada adubação de cobertura utilizando $45 \mathrm{~kg} \mathrm{ha}^{-1}$ de ureia.

O manejo das plantas daninhas antes da aplicação dos tratamentos foi realizado por meio de capinas manual.

A aplicação dos tratamentos foi realizada em 30/10/2013 quando a braquiária apresentava pleno desenvolvimento $(53,0 \pm 1,5$ $\mathrm{m}$ de altura e antes do florescimento) e cobriu totalmente a superfície do solo das parcelas. A 
quantidade de matéria seca no momento das aplicações correspondeu em média a $4.188,0 \mathrm{~kg}$ $\mathrm{ha}^{-1}$. As aplicações foram realizadas no período da tarde com condições climáticas de 21,8 a $35,1^{\circ} \mathrm{C} ; 53$ a $75 \%$ de umidade relativa do ar e 0,8 a $1,3 \mathrm{~m} \mathrm{~s}^{-1}$ de velocidade do vento. Foi utilizando pulverizador costal pressurizado a $\mathrm{CO}_{2}$, com pressão constante, equipado com seis pontas, espaçadas em $0,5 \mathrm{~m}$ e posicionadas a 0,5 $\mathrm{m}$ do alvo.

A soja 'SYN 1059 RR' foi semeada (07/11/2013) após o término da avaliação da dessecação da forrageira (7 dias após a aplicação do herbicida), no espaçamento de 0,45 m. A adubação de base foi de $290 \mathrm{~kg} \mathrm{ha}^{-1}$ do formulado 2-23-23. Cada unidade experimental foi constituída de seis linhas, em uma área total de $15,0 \mathrm{~m}^{2}$ (3 $\mathrm{m}$ de largura $\mathrm{x} 5 \mathrm{~m}$ de comprimento).

Avaliação da dessecação da forrageira foi realizada visualmente por meio dos efeitos de intoxicação das plantas de B. ruziziensis, utilizando-se uma escala de percentual de notas, na qual 0 (zero) corresponde a nenhuma injúria demonstrada pela planta e 100 (cem) à morte das plantas, segundo a Sociedade Brasileira da Ciência das Plantas Daninhas - SBCPD (1995). Os parâmetros utilizados para estabelecimento das notas foram: inibição do crescimento, quantidade e uniformidade das injúrias, capacidade de rebrota das plantas, quantidade de plantas mortas e acúmulo de biomassa.

As avaliações de dessecação foram realizadas aos 3 e 7 dias após a aplicação (DAA). Por ocasião da colheita da soja (11/03/2014), foram avaliadas a matéria seca da forrageira, para determinar o acúmulo de biomassa e a quantidade de palhada remanescente na área. Para isso, coletou-se a parte aérea das forrageiras, utilizando-se uma moldura metálica de $0,25 \mathrm{~m}^{2}$ de área, em uma amostragem por unidade experimental. $\mathrm{O}$ material coletado foi seco em estufa de circulação forçada de ar a $60^{\circ} \mathrm{C}$; em seguida, pesado, e os dados, transformados em kg ha-1.
$\mathrm{Na}$ cultura da soja determinou-se a densidade de plantas por metro linear e foram colhidas as plantas manualmente das quatro linhas da área útil das parcelas. A colheita da soja foi feita aos 124 dias após a semeadura (DAS).Após a colheita efetuou-se a degrana dos grãos mecanicamente, a limpeza e a correção da umidade para $13 \%$.

Foi realizada a avaliação da comunidade de plantas daninhas na área de cada tratamento por meio do método do quadrado inventário, utilizando-se quadros de $0,25 \mathrm{~m}^{2}(0,5 \times 0,5 \mathrm{~m})$, lançados uma vez ao acaso em cada parcela. Em cada unidade experimental as plantas daninhas foram contadas e identificadas segundo família, espécie e nome comum.

O levantamento das plantas daninhas foi realizado no $18^{\circ}$ dia após a colheita da soja. Neste período também, foram coletadas as plantas daninhas presentes nos quadrados, secas e pesadas para a determinação da matéria seca.

Os resultados referentes à porcentagem de dessecação da forrageira, densidade de plantas por ocasião da colheita da cultura, produtividade de grãos e produção de matéria seca da forrageira foram submetidos à análise de variância - ANOVA pelo teste ' $\mathrm{F}$ ' $(P \leq 0,05)$, e as médias foram ajustadas a modelos de regressão, sendo as equações escolhidas com base nos modelos significativos $(P \leq 0,05)$, com normalidade, com lógica biológica e de elevado $\mathrm{R}^{2}$.

\section{Resultados e Discussão}

Na Tabela 2 está apresentado o resumo da análise de variância dos parâmetros avaliados no manejo da dessecação de $B$. ruziziensis com diferentes doses do paraquat e de volumes de calda antecedendo a semeadura da soja. Verificou-se que houve apenas interação entre os fatores doses do paraquat e de volumes de aplicação para os dados de porcentagem de dessecação da forrageira aos 7DAA. 
Tabela 2. Quadrado médio da análise de variância dos parâmetros avaliados no manejo da dessecação da $B$. ruziziensis com diferentes doses do paraquat e de volumes de calda antecedendo a semeadura da soja. Marechal Cândido Rondon/PR.

\begin{tabular}{|c|c|c|c|c|c|}
\hline \multirow{2}{*}{$\mathrm{FV}$} & \multicolumn{2}{|c|}{ \% de dessecação } & \multirow{2}{*}{ 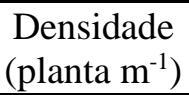 } & \multirow{2}{*}{$\begin{array}{l}\text { Produção } \\
\left(\mathrm{kg} \mathrm{ha}^{-1}\right)\end{array}$} & \multirow{2}{*}{$\begin{array}{l}\text { Massa secada forrageira } \\
\qquad\left(\mathrm{kg} \mathrm{ha}^{-1}\right)\end{array}$} \\
\hline & $3 \mathrm{DAA}$ & $7 \mathrm{DAA}$ & & & \\
\hline Dose (D) & $228,73^{*}$ & $870,63^{*}$ & $117,12^{*}$ & $7898740,52^{* *}$ & $3677659,78^{\mathrm{ns}}$ \\
\hline Volume (V) & $57,86^{*}$ & $428,25^{*}$ & $31,88^{*}$ & $211326,39^{*}$ & $17730820,44^{\mathrm{ns}}$ \\
\hline (D) $\mathrm{x}(\mathrm{V})$ & $9,59^{\mathrm{ns}}$ & $95,98^{* *}$ & $14,42^{\mathrm{ns}}$ & $81678,77^{\mathrm{ns}}$ & $24078220,19^{\mathrm{ns}}$ \\
\hline Exp. x Trat. Adic. & $34405,65^{\mathrm{ns}}$ & $30673,50^{\mathrm{ns}}$ & $105,42^{\mathrm{ns}}$ & $14788021,57^{\mathrm{ns}}$ & $38603906,64^{\mathrm{ns}}$ \\
\hline Blocos & 93,31 & 104,00 & 25,23 & 115184,38 & 121970805,90 \\
\hline Erro & 8,33 & 54,49 & 8,83 & 6560629,70 & 22861716,97 \\
\hline $\mathrm{CV}(\%)$ & 3,10 & 8,30 & 69,80 & 93,00 & 38,60 \\
\hline
\end{tabular}

**Significativo a $1 \%$ de probabilidade pelo teste ' $\mathrm{F}$ '; *Significativo a $5 \%$ de probabilidade pelo teste ' $\mathrm{F}$ ' $\mathrm{e}^{\text {ns }}$ não significativo.

$\mathrm{Na}$ Figura 1 estão apresentadas as porcentagens de dessecação de B. ruriziensis em diferentes dias após a aplicação do paraquat com distintas doses e de volumes de calda. Pode-se verificar aos 3DAA que as doses do paraquat, independentemente do volume de calda utilizado, apresentaram excelente eficiência na dessecação da forrageira (Figura 1A).

$\mathrm{Na}$ avaliação realizada aos 7DAA, verificou-se que a eficiência na dessecação de $B$. ruriziensis foi reduzida devido à ocorrência de emissão de nova brotação das plantas, principalmente quando se utilizou a menor dose do paraquat $\left(100 \mathrm{~g} \mathrm{ha}^{-1}\right)$ em volumes superiores a $250 \mathrm{~L} \mathrm{ha}^{-1}$ (Figura 1B). Provavelmente, nestas condições tenham ocorrido perdas da calda por escorrimento, uma vez que, quando se utilizou a mesma dose em menores volumes de aplicação houve maior eficiência na dessecação da forrageira. Ressalta-se que por ocasião deste período foi realizada a semeadura da soja.

Na Figura 2 estão descritos os dados de densidade de plantas de soja por ocasião da colheita. Pode-se verificar que na medida em que se aumentou a dose do paraquat e o volume de aplicação foram obtidas densidades semelhantes à da testemunha correspondente à soja cultivada sem a presença da palhada da $B$. ruziziensis $\left(9,5\right.$ plantas $\left.\mathrm{m}^{-1}\right)$.

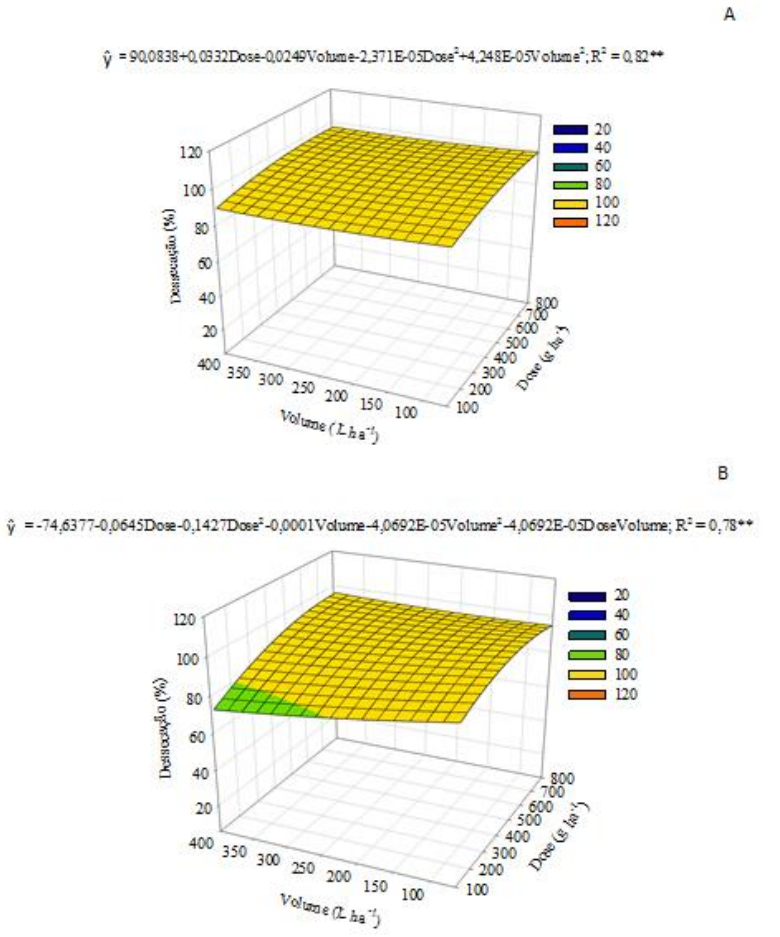

3DAA (A) e 7 DAA (B). ${ }^{* *}$ Significativo a $1 \%$ de probabilidade pelo teste ' $F$ '.

Figura 1. Porcentagem de dessecação de $B$. ruriziensis em diferentes dias após a aplicação do paraquat e de volumes de calda antecedendo a semeadura da soja. Marechal Cândido Rondon/PR.

Estes resultados ressaltam a importância da maior eficiência na dessecação de $B$. ruziziensis para evitar o efeito negativo da palhada no momento da semeadura da cultura (barreira física a germinação das sementes) e da ocorrência de rebrote das plantas da forrageira 
que podem interferir negativamente durante no desenvolvimento da cultura e causar reduções significativas de produtividade (Figura 3).

$\hat{y}=-0,5617-0,0196$ Dose-0,0152Dose $e^{2}-4,5214$ E- 05 Volume- $7,3648 E-05$ Volume $-7,3648 E-05$ DoseV olume; $R^{2}=0,72^{2 *}$

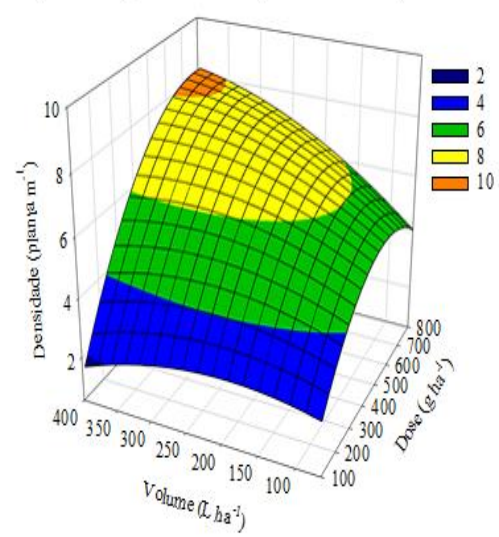

** significativo a $1 \%$ de probabilidade pelo teste ' $\mathrm{F}$ '.

Figura 2. Densidade de plantas de soja (planta $\mathrm{m}^{-1}$ ) por ocasião da colheita (124 dias após a semeadura da cultura). Marechal Cândido Rondon/PR.

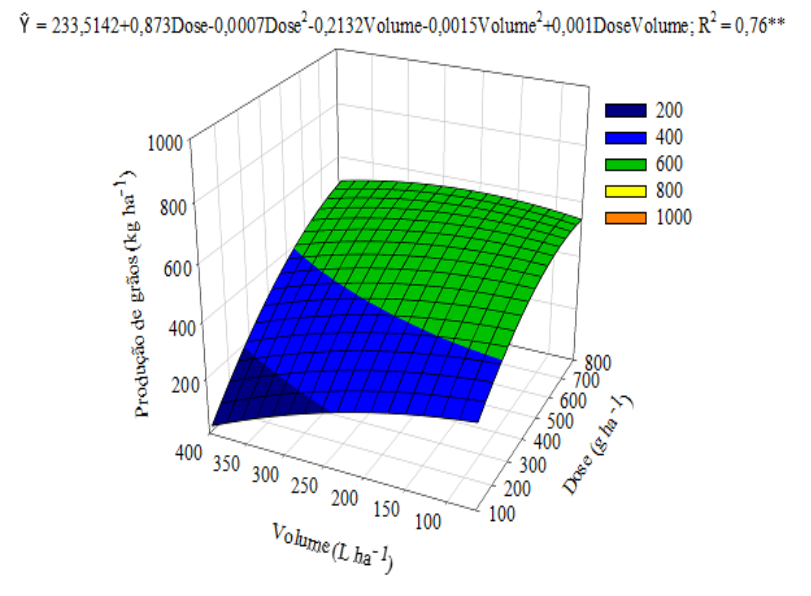

** significativo a $1 \%$ de probabilidade pelo teste ' $\mathrm{F}$ '.

Figura 3. Produção de grãos de soja após a dessecação de $B$. ruriziensis com diferentes doses de paraquat e de volumes de calda. Marechal Cândido Rondon/PR.

A convivência da cultura da soja com as plantas de $B$. ruziziensis causou redução média de $86,8 \%$ na produção de grãos em relação à testemunha correspondente a soja cultivada sem a presença da palhada daforrageira. Enquanto que a testemunha correspondente a soja cultivada sem a presença da palhada de $B$. ruziziensis produziu $2287,0 \mathrm{~kg} \mathrm{ha}^{-1}$.

Pacheco et al. (2009), revelaram que a soja 'MSOY 6101' cultivada sobre a palhada da B. ruziziensis $\left(7.250 \mathrm{~kg} \mathrm{ha}^{-1}\right)$ após a dessecação com glyphosate (1.900 $\left.\mathrm{g} \mathrm{ha}^{-1}\right)$ e 2,4-D (335 $\mathrm{g} \mathrm{ha}^{-}$ $\left.{ }^{1}\right)$ não apresentou redução do estande de plantas e nem da produtividade da cultura. Os autores citam ainda que, o sistema de corte e a deposição de adubo e semente da semeadora-adubadora foram suficientes para deixar na linha de plantio um sulco entre as palhadas, que favoreceu a incidência de luminosidade, contribuindo para a germinação e o crescimento da cultura anual.

Acreditamos que estes resultados podem ser explicados devido a utilização de herbicidas sistêmicos na dessecação da forrageira que exigem maior tempo para promover efeito satisfatório antes da semeadura da cultura, além de não permitir rebrota da forrageira o que consequentemente evitou a competição pelos fatores de crescimento com a cultura.

$\mathrm{Na}$ Tabela 3 pode-se observar que a quantidade de matéria seca das plantas de $B$. ruziziensis após a colheita da soja correspondeu à média de $12.300,1 \mathrm{~kg} \mathrm{ha}^{-1}$, independente do tratamento utilizado, corroborando com os resultados obtidos por Pacheco et al. (2008). Este fato evidencia o bom potencial de $B$. ruziziensis em produzir biomassa mesmo após o manejo da dessecação com o paraquat, devido a rebrota das plantas.

Considerando estes resultados para o sistema de integração lavoura-pecuária, pode-se inferir que devido à capacidade de rebrota de $B$. ruziziensis após a dessecação com paraquat e da semeadura da soja, haveria a possibilidade de excluir a necessidade de realizar nova semeadura da forrageira para a produção de palhada para o plantio direto da próxima cultura ou para formação de pastagem (Ferri et al., 2001; Costa et al., 2013). Entretanto, deve-se utilizar meios de se evitar os efeitos negativos da convivência entre a forrageira e a cultura de interesse principalmente durante o período crítico de prevenção de interferência (PCPI). 
De acordo com Saraiva et al. (2013), $B$. ruziziensis semeada nas densidades de 5 a $10 \mathrm{~kg}$ $\mathrm{ha}^{-1}$ aos 12 e 24 dias após a emergência (DAE) da soja 'M-8766 RR', não causou redução na produtividade da cultura. Segundo Silva et al. (2004), foi necessário aplicar $54 \mathrm{~g} \mathrm{ha}^{-1} \mathrm{de}$ fluazifop-p-butil sobre $B$. brizantha, aos 21 DAE da soja 'UFV-16' em consórcio, para obter produtividade semelhante ao da testemunha.
Em outro estudo, Silva et al. (2006), citam que o consórcio entre a soja 'UFV-16' e B. brizantha, submetida a $15 \mathrm{~g} \mathrm{ha}^{-1}$ de fluazifopp-butil aos 23 DAE da cultura e a dessecação no estádio R7 da soja, permitiu a colheita mecânica com produção de grãos semelhante à alcançada no monocultivo.

Tabela 3. Matéria seca $\left(\mathrm{kg} \mathrm{ha}^{-1}\right)$ das plantas de $B$. ruziziensis 18 dias após a colheita da soja.Marechal Cândido Rondon/PR.

\begin{tabular}{ccccccc}
\hline \multirow{2}{*}{ Paraquat $\left(\mathrm{g} \mathrm{ha}^{-1}\right)$} & \multicolumn{7}{c}{ Volume de Aplicação $\left(\mathrm{L} \mathrm{ha}^{-1}\right)$} \\
\cline { 2 - 6 } & 67 & 140 & 199 & 283 & 323 & 396 \\
\hline 100 & 13332,7 & 14164,8 & 11060,8 & 12757,8 & 10818,1 & 15634,7 \\
200 & 13590,5 & 11278,8 & 12221,7 & 10008,0 & 14621,4 & 10772,3 \\
400 & 8174,3 & 11328,6 & 13027,0 & 13013,3 & 11263,3 & 17449,3 \\
800 & 16575,8 & 10729,4 & 8897,3 & 11617,4 & 12160,9 & 13177,1 \\
\hline Testemunha* & \multicolumn{7}{c}{15573,8} \\
\hline
\end{tabular}

*A testemunha corresponde a forrageira solteira e sem a aplicação do herbicida.

Na Figura 4 podem ser observados os dados de matéria seca das plantas daninhas coletadas, logo após a colheita da soja, cultivada após a dessecação de $B$. ruriziensis com diferentes doses de paraquat e de volumes de aplicação. Constatou-se que a presença de $B$. ruziziensis durante o desenvolvimento da soja promoveu redução da biomassa da comunidade das plantas daninhas, bem como proporcionou excelente controle destas espécies.

Castro et al. (2011), relataram que a presença de $B$. ruziziensis no sistema safraforrageira (soja + braquiária/milho + braquiária/arroz + braquiária/soja) proporcionou a maior redução de matéria seca das plantas daninhas e na quantidade de plantas daninhas na área, proporcionando ótimo controle, em relação ao pousio $(97,7 \%)$.

A comunidade das plantas daninhas presente na área experimental foi composta por 9 famílias e 15 espécies, destacando-se as famílias Asteraceae e Poaceae, com três e cinco espécies em cada uma, respectivamente (Tabela 4).

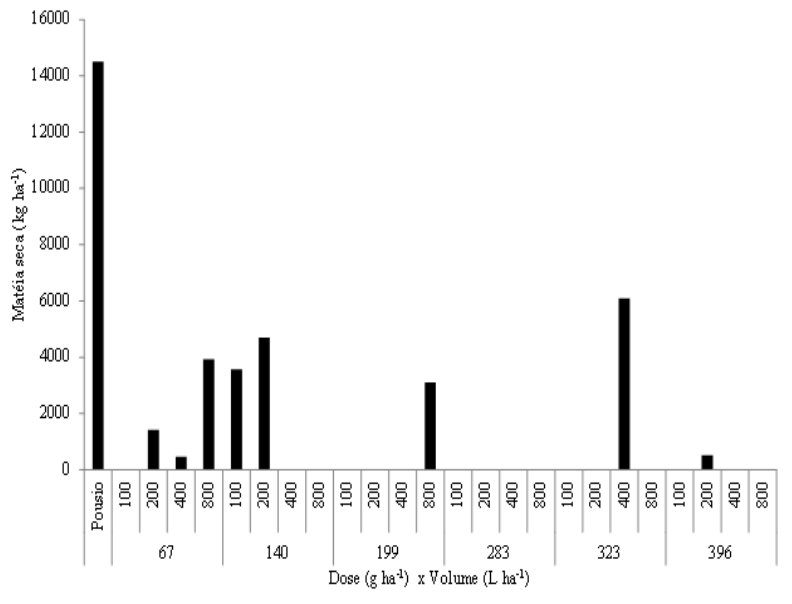

Figura 4. Matéria seca das plantas daninhas coletadas 18 dias após a colheita da soja, cultivada após a dessecação de $B$. ruriziensis com diferentes doses de paraquat e de volumes de calda. Marechal Cândido Rondon/PR.

As espécies B. pilosa, C. benghalensis, D. insularis, S. americanum, Ipomoeasp. e $S$. halepense também foram encontradas em outras áreas sob sistema de integração agriculturapecuária (Ikeda et al.; 2007, Borghi et al., 2008; Castro et al., 2011; Machado et al., 2011; Ikeda et al., 2013). Este fato demonstra a possibilidade 
de seleção de espécies adaptadas ao sistema de integração agricultura-pecuária. Em contrapartida, este sistema de produção pode auxiliar no manejo integrado de espécies comprovadamente tolerantes ou resistentes aos herbicidas a exemplo da $B$. pilosa, $C$. benghalensis, $C$. bonariensis, D. insularis, $E$. heterophylla e $S$. halepense (Beckie e Reboud, 2009; Mello et al., 2012; Vencill et al., 2012).

Ressalta-se ainda que o efeito rápido do paraquat na dessecação das plantas seria interessante para ocasiões em haja a necessidade de se iniciar as operações de semeadura da cultura o mais urgente possível, seja por questões operacionais, climáticas ou de zoneamento agrícola. Contudo, mais estudos são necessários para se evitar a interferência da forrageira sobre o desenvolvimento e produtividade da cultura em consórcio, sem que ocorra prejuízo na formação de biomassa para o sistema de plantio direto ou para o pastejo de animais.

Tabela 4. Família, nome científico e comum das espécies de plantas daninhas presente na área experimental,18 dias após a colheita da soja.Marechal Cândido Rondon/PR.

\begin{tabular}{lcc}
\hline \multicolumn{1}{c}{ Família } & Nome Científico & Nome Comum \\
\hline Asteraceae & Bidens pilosa & Picão preto \\
& Conyza bonariensis & Buva \\
& Vernonia polysphaera & Assa-peixe \\
\hline Commelinaceae & Commelina benghalensis & Trapoeraba \\
\hline Convolvulaceae & Ipomoea sp. & Corda-de-viola \\
\hline Euphorbiaceae & Euphorbia heterophylla & Leiteiro \\
\hline Malvaceae & Sida spinosa & Guanxuma \\
\hline Phyllanthaceae & Phyllanthus tenellus & Quebra-pedra \\
\hline & Chloris polydactyla & Capim-guayamum \\
& Digitaria horizontalis & Capim colchão \\
Poaceae & Digitaria insularis & Capim amargoso \\
& Digitaria insularis & Capim amargoso \\
& Sorghum halepense & Vassourinha \\
\hline Rubiaceae & Richardia brasiliensis & Poáia branca \\
\hline Solanaceae & Solanum americanum & Maria preta \\
\hline
\end{tabular}

Já foi constatado que herbicidas sistêmicos apresentam efeito relativamente mais lento na dessecação das plantas de $B$. ruziziensis. Uma vez que, Costa et al. (2013), observaram que o glyphosate nas doses de 720 e $1440 \mathrm{~g} \mathrm{ha}^{-1}$ apresentaram eficiência de $93 \mathrm{e}$ $98 \%$ na dessecação desta forrageira a partir dos 28 DAA. Período até três vezes superior ao que pode ser obtido com o uso do paraquat no manejo da área para a semeadura da cultura.

Outra observação importante foi que devido o rápido efeito do paraquat, as plantas de B. ruziziensis ainda permanecem eretas e a palhada em grande quantidade $\left(4.188,0 \mathrm{~kg} \mathrm{ha}^{-1}\right)$ pode ter obstruído o sulco de semeadura e prejudicado a emergência da soja, ao contrário do que acontece com o uso do glyphosate, que apresenta efeito mais lento e permite que a palhada já em processo de decomposição se acomode sobre o solo, facilitando o corte da palha e sem ocorrer obstrução do sulco de semeadura.

\section{Conclusões}

Com base nos resultados obtidos no presente trabalho, pode-se concluir que, a dessecação de $B$. ruziziensis com paraquat nas doses e volume de calda avaliados foram eficientes até aos 7 DAA, sendo o paraquat mais eficiente a partir da dose de $200 \mathrm{~g} \mathrm{ha}^{-1}$, independentemente do volume de aplicação. 
Enquanto que, a partir destes períodos as plantas da forrageira iniciaram um novo ciclo de crescimento e interferiram negativamente na produtividade da soja.

A infestação das plantas daninhas foi reduzida nas áreas com B. ruziziensis em consórcio com a soja em relação às áreas em pousio.

\section{Agradecimentos}

Agradecemos ao $\mathrm{CNPq}$ pela disponibilização do auxílio financeiro para a realização do presente trabalho de pesquisa.

\section{Referências}

ARAÚJO, A.G.; RODRIGUES, B.N. Manejo mecânico e químico da aveia preta e sua influência sobre a taxa de decomposição e o controle de plantas daninhas em semeadura direta de milho. Planta Daninha, v.18, n.1, p.151-160, 2000.

BAUER, F.C.; RAETANO, C.G. Distribuição volumétrica de calda produzidas pelas pontas pulverização XR, TP e TJ sob diferentes condições operacionais. Planta Daninha, v.22, n.2, p.275-284, 2004.

BECKIE, H.J.; REBOUD, X. selecting for weed resistance: herbicide rotation and mixture. Weed Technology, v.23, n.3, p.363-370, 2009.

BORGHI, E. et al. Influência da distribuição espacial do milho e da Brachiaria brizantha consorciados sobre a população de plantas daninhas em sistema plantio direto na palha. Planta Daninha, v.26, n.3, p.559-568, 2008.

CASTRO, G.S.A. et al. Sistemas de produção de grãos e incidência de plantas daninhas. Planta Daninha, v.29, n.esp., p.1001-1010, 2011.

COSTA, N.V. et al. Avaliação do glyphosate e paraquat no manejo da Brachiaria ruziziensis. Revista Brasileira de Herbicidas, v.12, n.1, p.31-38, 2013.
CUNHA, J.A.R.; TEIXEIRA, M.M., FERNANDES, H.C. Avaliação do espectro de gotas de pontas de pulverização hidráulicas utilizando a técnica da difração do raio laser. Engenharia Agrícola, v.27, n.esp., p.10-15, 2007.

EMPRESA BRASILEIRA DE PESQUISA AGROPECUÁRIA - Embrapa. Sistema brasileiro de classificação dos solos. Rio de Janeiro: 1999. 412 p.

FERRI, M.V.W.; ELTZ, F.L.F.; LOPES, S.J. Aplicação de herbicidas dessecantes em pastagens nativas constituídas por diferentes espécies do gênero Paspalum. Ciência Rural, v.31, n.4, p.589-595, 2001.

IKEDA, F.S. et al. Banco de sementes no solo em sistemas de cultivo lavoura-pastagem.

Pesquisa Agropecuária Brasileira, v.42, n.11, p.1545-1551, 2007.

IKEDA, F.S. et al. Interferências no consórcio de milho com Urochloa spp. Ciência Rural, v.43, n.10, p.1763-1770, 2013.

JAKELAITIS, A. et al. Dinâmica populacional de plantas daninhas sob diferentes sistemas de manejo nas culturas de milho e feijão. Planta Daninha, v.21, n.1, p.71-79, 2003.

KISSMANN, K.G.; GROTH, D. Plantas infestantes e nocivas. 2.ed. São Paulo: BASF, 1997. Tomo I. 825 p.

MACHADO, V.D. et al. Fitossociologia de plantas daninhas em sistemas de integração de sorgo com braquiária sob diferentes formas de implantação da pastagem. Planta Daninha, v.29, n.1, p.85-95, 2011.

MATEUS, G.P.; CRUSCIOL， C.A.C.; NEGRISOLI, E. Palhada do sorgo de guiné gigante no estabelecimento de plantas daninhas em área de plantio direto. Pesquisa Agropecuária Brasileira, v.39, n.6, p.539-542, 2004.

MELLO, M.S.C. et al. Alternativas para o controle químico de capim-amargoso (Digitaria insularis) resistente ao glyphosate. Revista 
Brasileira de Herbicidas, v.11, n.2, p.195-203, 2012.

PACHECO, L.P. et al. Desempenho de plantas de cobertura em sobressemeadura na cultura da soja. Pesquisa Agropecuária Brasileira, v.43, n.7, p.815-823, 2008.

PACHECO, L.P. et al. Sobressemeadura da soja como técnica para supressão da emergência de plantas daninhas. Planta Daninha, v.27, n.3, p.455-463, 2009.

RODRIGUES, B.N.; ALMEIDA, F.S. Guia de herbicidas. $6^{\mathrm{a}}$ ed. Londrina, 2011, 697p.

SARAIVA, A.S. et al. Density and sowing season of two brachiaria species on the soybean culture. Planta Daninha, v.31, n.3, p.569-576, 2013.

SEVERINO, F.J.; CHRISTOFFOLETI, P.J. Efeitos de quantidades de fitomassa de adubos verdes na supressão de plantas daninhas. Planta Daninha, v.19, n.2, p.223-228, 2001.

SILVA, A.C. et al. Dessecação pré-colheita de soja e Brachiaria brizantha consorciadas com doses reduzidas de graminicida. Pesquisa Agropecuária Brasileira, v.41, n.1, p.37-42, 2006.

SILVA, A.C. et al. Efeitos de doses reduzidas de fluazifop-p-butil no consórcio entre soja e Brachiaria brizantha. Planta Daninha, v.22, n.3, p.429-435, 2004.

SOCIEDADE BRASILEIRA DA CIÊNCIA DAS PLANTAS DANINHAS-SBCPD. Procedimentos para instalação, avaliação e análise de experimentos com herbicidas. Londrina: 1995. 42p.

SPRAYING SYSTEMS Co. Teejet: catálogo 50A-P. Wheaton: Illinois, E.U.A., 2008. 192 p.

VENCILL, W.K. et al. Herbicide resistance: toward an understanding of resistance development and the impact of herbicideresistant crops. Weed Science, v.60, n.esp., p.230, 2012. 